\title{
Organizational Determinants of Whistleblowing. A Study of Italian Municipalities
}

\author{
Pietro Previtali $^{1}$ (D) Paola Cerchiello ${ }^{1}$
}

Accepted: 6 August 2021 / Published online: 25 August 2021

(c) The Author(s) 2021, corrected publication 2022

\begin{abstract}
The aim of this paper is to provide a deeper understanding of how to develop whistleblowing systems in public administrations, by focussing on the organisational variables that lead to actual reporting being made. The research is based on an empirical analysis of 400 major Italian municipalities and the whistleblowing systems they have implemented as anti-corruption measures. The results show that actual reporting is positively correlated with the presence of specific whistleblowing procedures as well as training and education programs. Anonymous reporting plays a relevant role.
\end{abstract}

Keywords Whistleblowing · Corruption - Municipalities · Public administrations · Organizational procedures · Anti-corruption programs

\section{Introduction}

Whistleblowing and tip offs in general are among the most effective ways to detect frauds and corruption If corruption is approached through the lens of principalagent theory, it is possible to see as corruption depends on "information asymmetries between principal and agent” (Van Schoor, 2017, p. 19), and how whistleblowing can be one of the few systems that can help to reduce these asymmetries. The 2018 Association of Certified Fraud Examiners (ACFE) Report to the Nations, based on 2,690 analyses of frauds in 125 countries highlights that $40 \%$ of frauds are detected through tip offs. Similar results were found in an analysis conducted by KPMG (2016). In general, statistics on frauds and corruption are alarming. The Eurobarometer Report on Corruption (2020) shows that $70 \%$ of respondents

Pietro Previtali

Pietro.previtali@unipv.it

Paola Cerchiello

Paola.cerchiello@unipv.it

1 Department of Economics and Management Sciences, University of Pavia, Via San Felice 7, 27100 Pavia, Italy 
consider corruption a widespread and systemic phenomenon in their country. The Transparency International's Global Corruption Barometer Report (2017) stated that "around the world nearly 1 in 4 people said that they paid a bribe for public services in the 12 months prior to when the survey took place". Hence, it is evident that governments and companies must react to this situation, also by investing in more effective methods of detecting wrongdoing and corruption. Nowadays, most countries have legislation that provides for an anti-corruption system and whistleblowing procedures (Vandekerckhove \& Lewis, 2012). Some scholars (Mansbach 2007; Rachagan \& Kuppusamy, 2013) have demonstrated that the law is not sufficient. From here it begins this study, with the aim of developing a deeper understanding of the organisational variables that impact most on whistleblower reporting. Organisational variables and aspects that are the less studied component of the fraud triangle framework. In addition, it is argued that this research is also relevant since until recently and as stated by De Graaf (2019) and Taylor (2018), most of the studies on whistleblowing have analysed the intention and the propensity to blow the whistle, while less studies have focused on actual reporting. For whistle blower reporting here it is intended the actual action of reporting a misconduct that an employee communicates to the compliance officer, that can be made through different systems, such as paper, e-mail, and dedicated information systems.

\section{Literature Review and Hypothesis Development}

As stated by Peerthum and Luckho (2021) "corruption has now become a very pertinent issue affecting all spheres of our modern society". Shah (2007) defined four types of corruption exist: (a) the first is called bureaucratic corruption, that occurs when public officials abuse their office by demanding bribes and kickbacks; this form is to focus of our study; (b) the second is called grand corruption, and concerns large amount of money stolen by public officials; (c) the third type occurs when public officials are trapped by the private sector; (d) the fourth type is called patronage or clientelism. A large body of evidence shows that corruption damage the quality of public institutions (Bauhr \& Charron, 2020; Chan et al., 2020; Previtali \& Cerchiello, 2018a). In literature, several studies demonstrated as corruption reduces investment, productivity and economic growth (Liu et al., 2017; Wu et al., 2017; Cooray et al., 2017; Capasso et al., 2019; Schomaker, 2020, Akimova et al., 2020). Concerning anti-corruption measures, as stated by Baniamin and Jamil (2018) "The limited success of anticorruption measures points to the need to generate a better understanding of the problem of corruption and to explore effective measures for controlling it". Persson et al. (2013) define anticorruption interventions as a problem of "collective action". As stated by Previtali and Cerchiello (2017) "dealing with corruption there are no simple answers". Given this situation, whistleblowing is one of the most important way that a community has to contrast and prevent corruption. Whistleblowing is a well-studied phenomenon with more than 30 years of research (Miceli et al. 2009). More recently an interesting critical review and research agenda was provided by Culiberg and Mihelic (2017), that suggest a framework of analysis based on five questions: who, what, how, why and to whom to blow the whistle. 
In this literature review, it is dedicated a particular interest to research that deals with actual whistleblowing and how organisational variables impact on whistleblowing. Some scholars focussed their attention on internal whistleblowing and actual reporting. Smith (2010) conducted a research called "Whistling While They Work" from 2005 and 2007, that involved several hundred whistleblowers, managers, and case handlers across 304 Australian public sector agencies. He found that whistleblowing is more common than previously imagined, and that whistleblowers tend to prefer internal channels for reporting wrongdoing. Also Taylor (2018) observed strong relations between employee perceptions of trustworthiness of different organisational members and internal whistle-blowing, through a sample of 10,850 whistleblowers in 60 Australian Public Organisations from 2013 to 2016. Other scholars conducted their research on external whistleblowing and actual reporting. Park and Lewis (2019) analysed a sample of 127 external whistleblowers in South Korea. They found that morality was the most important factor that impacts on the actual decision of whether or not to blow the whistle, while the fear of retaliation and other negative consequences had a significant negative effect on actual whistleblowing. Smaili and Arroyo (2019) conducted a comparative study of 11 cases of whistleblowing of Canadian companies that were publicly denounced between 1995 and 2012. They proposed four conceptual types of whistleblowers, and they highlighted the relevance of external whistleblowers and of external channels for actual reporting, such as the relevance of financial benefits. Finally, some studies developed a quantitative exploration of whistleblowing as a protracted process, rather than a single action (Vandekerckhove and Phillips, 2019). Concerning the relationship between organisational variables and whistleblowing we agree with Park and Lewis (2019) that "organisational variables such as organisational structure, perceived responsiveness of the organisation, and a culture of organisational justice can influence the whistleblowing act'. According to King (1999) organisational structure is related to the probability and type of whistleblowing. Miceli et al., (1991, 2009) King (1999) and more recently Cooper (2021) found a positive relation between whistleblowing and the use of formalisation, standardisation and hierarchical communication and formal procedures. Some studies suggest a positive relationship between procedures and specific organisational policies and whistleblowing (Hassink et al., 2007; Keenan 1990; Barnett, 1992; Cassematis \& Wortley, 2013). Palumbo and Manna (2020) found a positive relationship between whistleblowing and ICT-based procedures in academic institutions. Previtali and Cerchiello (2018b) found a positive relationship between whistleblowing, organisational size and formal procedures and proceduralisation in a sample of 365 public administrations. In addition, if it is considered that one of the most critical aspects of whistleblowing is the threat of retaliation (Caillier \& Sa, 2017), mechanisms and procedures that protect the identity of whistleblowers, and provide clear procedural steps with a range of available reporting methods, can lead employees to blow the whistle (Gundlach et al., 2003; Mesmer-Magnus \& Viswesvaran, 2005; Miceli et al., 2009). Another organisational variable observed in literature is training and anti-corruption education programs. Smith's, 2010 WWTW study identified education and training as one of the most important ways to promote the culture of whistleblowing, to promote an integration between a compliance-based approach and an integrity-based approach 
(Calderon et al., 2018). That is, it is not enough to respect the law and to implement a whistleblowing procedure. If we want employees to blow the whistle and to report wrongdoing, we have also to implement a cultural change, and for this to take place, training and education programs are crucial (Chordiya et al., 2020; Mazerolle \& Brown, 2008; Rachagan \& Kuppusamy, 2013). More in general, Tantardini and Garcia-Zamor (2015) asked what causes the failure of anticorruption systems. They summed up three factors: (a) the failure in designing anticorruption; (b) the failure in implementation process; (c) the dependence of corruption on cultural factors. Starting from these studies, it is developed a research model (Fig. 1) that investigates the relations between whistleblowing and two organisational variables, in particular it is identified the following research hypotheses:

- HP1: There is a positive correlation between the implementation of whistleblowing procedures and whistleblowing reports;

- HP2: There is a positive relationship between training and anti-corruption education programs and whistleblowing reports.

\section{Research Context and Methodology}

\section{Research Context}

In Italy corruption and frauds against public administration represents one of the more critical challenges for central and local government, as shown by Transparency International's corruption perceptions index. In their last report (2020) Italy was ranked $52^{\circ}$ out of the 180 observed countries. In Annex 1 to the EU Anti-Corruption Report the European Commission wrote "corruption remains a serious challenge in Italy [...]. In reaction to this situation and under pressure from international organisms, the Italian Government issued Law no. 190 in 2012, the so-called anticorruption law, since it introduced for the first time a systematic approach to fighting corruption in Italian public administrations. This law made the introduction of a whistleblowing system compulsory for all Italian public administrations. Afterwards it issued Law no. 179 in 2017, which provides for specific measures to protect the whistleblower's identity as well as indications on how to deal with whistleblower

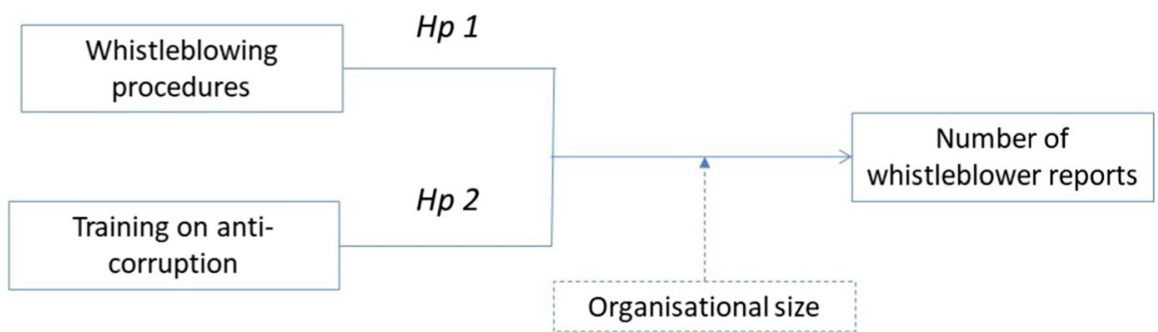

Fig. 1 Research model 
reporting, and the obligatory introduction of a whistleblowing system in the private sector.

\section{Research Methodology}

Figure 1 shows the research model. Each hypothesis is tested through a count model represented by the multivariate Poisson regression model, followed by a stepwise selection procedure based on the AIC index (Akaike Information Criterion) to evaluate the best model configuration in terms of significant variables. This choice is due to the nature of the data at hand. The target variable, as already stated, refers to the number of whistleblowing reports so it naturally represents counts.

The first independent variable is the implementation of specific whistleblowing procedures. It is measured through a dummy variable which identifies whether or not specific procedures are present. The article gathered four years of data (2014-2017). The second independent variable is training and education programs on anti-corruption. It is measured through a dummy variable which identifies whether or not education and training programs are present. The dependent variable is the number of whistleblowing reports received by the compliance officer, differentiated in anonymous and non-anonymous reporting. These reports are gathered by the public administrations both through specific whistleblowing procedures and non-specific procedures. The latter are letters and emails, anonymous or not, send directly to the compliance officer and/or to other officers without using the specific procedures and formats. ANAC doesn't provide data about how many reports are submitted by using or not specific whistleblowing procedures, nor does it provide data about the outcomes of the reporting process. The source for all the observed variables is the annual reports that all public administrations have been required to submit to the ANAC and to publish on their web sites since 2014. Data are gathered from the web sites of the observed organisations. Taking into account the different channels used by municipalities as described above, it was created a new variable called 'Multiple Channels' that considers all of them. More specifically, it was summed up each specific procedure ranging from 0 (no procedures) to 4 (all of them available). In this way, it can be assessed a kind of total impact of the several tools put in place to act against corruption and frauds. The control variable is the size of the organisation. Since the total number of employees was not available, it was used the resident population (source: official database of the Central Department of Public Administration), given that in Italy there is a positive correlation between the two dimensions. This information was treated, properly scaled, as a control variable thorough the analysis so as to account for possible bias induced by comparing municipalities of different sizes. It was preferred to employ this approach instead of calculating the percentage of reports for each municipality as this would transform the nature of the target variable (from counts to percentages) and force the adoption of alternative models more suited to percentage data. Finally, by considering that most of the Italian public administrations have not respected the compulsory requirement of publishing data about whistleblowing and anti-corruption measures on their web sites, primarily in the first years of application (by avoiding to publish any data or 
by publishing reports with a lot of missing values), it was decided to analyse the 400 largest Italian Municipalities, ranging in size from 2,872,800 inhabitants to 24,372 inhabitants. In effect, it was noted that in most cases the lack of publication is associated with small and medium-sized public administrations. Nevertheless, as it can be seen in the following tables, there is a discrete number of municipalities (10-20\%) in the research that didn't fill in some sections of the annual report.

\section{Results and Discussion}

As it can be regarded in Table 1, the first year of implementation was a year of experimentation, 17 municipalities have reports, for a total number of 43 whistleblowing reports. After this first year, the use of the whistleblowing system became more mature, and basically follows a regular path. In 2015 there were 123 whistleblowing reports from 45 municipalities, in 2016172 reports from 43 municipalities, in 2017149 reports from 48 municipalities.

These results show that whistleblowing report in Italian municipalities is undergoing an evolution from an embryonic stage. Following the first year of implementation (2014) when there were some criticisms and a low responsiveness to change, the next 3 years show a consistent increase in the number of municipalities with at least one whistleblowing report. There is a trend towards a consolidation point, with an average of $11-12 \%$ of municipalities that reported claims, for an average of 3-4 a year. The use of an anonymous channel is not marginal, being used in about $25 \%$ of total reports in 2015, 18\% in 2016 and 39\% in 2017. Despite this trend, it can be stated that whistleblowing is still in an early stage, in particular if it is considered that Italy has a very high level of corruption according to the international ranking issued by the Transparency International and World Bank. One out of ten of the observed municipalities report wrongdoing, and almost a third of these reports are anonymous. It can be assumed that the pressures and barriers to whistleblowing, such as the risk of being fired or losing one's reputation, the fear of future retaliation and/or unfair treatment, led to a high presence of anonymous reporting and/ or are not adequately balanced by social, moral and financial incentives to blow the whistle. In our opinion and to react to this situation, it is necessary to act on the third

Table 1 Number of reports a year (2014-2017)

\begin{tabular}{lllll}
\hline & 2014 & 2015 & 2016 & 2017 \\
\hline Total number of reports & 43 & 123 & 172 & 149 \\
Whose Number of anonymous reports & NA & 31 & 31 & 58 \\
Number of municipalities with at least one report & 17 & 45 & 43 & 48 \\
Average number of reports per municipality & 2,5 & 2,7 & 4 & 3,1 \\
Maximum number of reports per municipality & 5 & 28 & 44 & 11 \\
Minimum number of reports per municipality & 1 & 1 & 1 & 1 \\
Standard deviation of number of reports & 1,11 & 1,34 & 1,79 & 1,81 \\
\hline
\end{tabular}


component of the fraud triangle, that is the opportunities provided by the organisational context to promote and to encourage whistleblowing. Hence the interest in organisational dimensions.

\section{The Relation between Procedures and Whistleblowing Reports}

Coming to the first organisational dimension of the research model, Table 2 shows the implementation of specific whistleblowing procedures by year. As above, the first year was an intermediary step. So, it is not surprising that $42 \%$ of the observed municipalities had not adopted a specific procedure for whistleblowing. Moreover, in 2014 there was also the lowest number of respondents to this section of the annual report (297 out of 400). Of the $58 \%$ of the observed municipalities that did implement specific whistleblowing procedures, the majority introduced a paper-based $(67 \%)$ and e-mail-based specific procedure (64\%), while only 5\% also used a specific dedicated information system and $2 \%$ a dedicated information system based procedure with internal cryptographic mechanisms. The situation changed in 2015 when the number of municipalities that used a specific procedure increased from 58 to $71 \%$, with a corresponding increase in the number of respondents that rises to 339 out of 400 . In this year, the use of paper-based (64\%) and e-mail-based specific procedures $(64 \%)$ and dedicated information system based procedures $(5 \%)$ remained the same. There was a significant increase in information systems with cybersecurity procedures, which rose from 2 to $19 \%$.

Overall, it can be considered an evolutionary pattern that becomes really very significant in 2016. This is probably related to the fact that in 2015 ANAC issued guidelines $\left(n^{\circ} 6 / 2015\right)$ with specific indications on the procedures and measures that public officers can follow to blow the whistle. This demonstrates that the process of whistleblowing needs a couple of years and some concrete indications and suggestions from the authorities. In fact, in 2016 the percentage of municipalities that adopt at least one specific procedure rises to $84 \%$ and the number of respondents to this section of the annual report to 363 out of 400 . The use of unsophisticated procedures remained essentially the same, whereas information system based procedures with internal cryptographic mechanisms rose to $23 \%$. Finally, in 2017 it can be noted a consolidation in the number of municipalities that adopt at least one whistleblowing procedure (88\%), with a further increase in the number of respondents $(374$ out of 400 municipalities). The use of all the channels remains substantially stable,

Table 2 Implementation of whistleblowing procedures

$2014 \quad 2015 \quad 2016 \quad 2017$

$\%$ of municipalities adopting one type of proceduralization at least

$58 \% \quad 71 \% \quad 84 \% \quad 88 \%$

$\%$ of municipalities adopting paper based procedure

$67 \% \quad 64 \% \quad 63 \% \quad 58 \%$

$\%$ of municipalities adopting e-mail based procedure

$64 \% \quad 64 \% \quad 65 \% \quad 63 \%$

$\%$ of municipalities adopting ad hoc information system based procedure

$5 \% \quad 5 \% \quad 6 \% \quad 7 \%$

$\%$ of municipalities adopting ad hoc encrypted information system based

$2 \% \quad 19 \% \quad 23 \% \quad 25 \%$

procedure 
however it can be noted a small decrease in paper-based procedures from 63 to $58 \%$, and in e-mail-based procedures that decrease from 65 to $63 \%$. Paper-based procedures consist in sending a letter to the compliance officer by external or in-house post. E-mail-based procedures consist in submitting the report via e-mail to a given e-mail address that it is viewed only by the compliance officer. There is an increase both in dedicated information systems from 6 to $7 \%$, and in dedicated information systems with encryption mechanisms from 23 to $25 \%$. Basically, even if the most common reporting procedures remain e-mail and paper-based procedures, there is a trend where the more advanced tools are tending to replace the basic ones. Coming to the first hypothesis, it is argued that there is a positive correlation between the implementation of specific whistleblowing procedures and whistleblowing reports. The research results in Table 3 confirm the positive relationship between the implementation of whistleblowing procedures and the number of reports of wrongdoing.

More precisely, difference in the logs of expected counts is expected to be 2.28 units higher for municipalities with procedures put in place compared to those without any procedures, while holding the other variables constant in the model. Once again, it can be noted an highly significant p-values for both the intercept and the variable 'Procedure'. The overall measures of goodness are reported as well and although significant, appear to be slightly smaller than the previous case. This relationship is confirmed for all types of specific procedures (Table 4): paper-based procedures, e-mail-based procedures and dedicated information systems with internal cryptographic mechanisms and security systems. The latter has the most positive correlation with the number of reports. The only exception concerns the municipalities who adopted ad hoc information system based procedures; here the empirical evidence was less clear and there was a significant coefficient only in some municipalities while in other cases, it was even negative.

The results demonstrate that for a whistleblower it is crucial to know who can blow the whistle, on what type of wrongdoing and how this should be done, if concerns can be raised in written or oral form, in person or via 'hotlines', confidentially or also anonymously. The presence of a clear and specific procedure that defines all the aspects described above, as well the roles and responsibilities about who is mandated to make investigatory decisions, who investigates concerns, who has operational responsibilities, and so on, make the difference between whether or not to blow the whistle. So the use of a mechanistic form of organisation where there is traditional pattern of hierarchy, reliance on formal rules and regulations, vertical

Table 3 Results from Poisson regression on $\mathrm{Hp} 1$

\begin{tabular}{llll}
\hline HP1 ROLE OF PROCEDURE & Constant & Procedure & Scaled Size \\
\hline $\mathrm{B}$ & $-3.39^{* * *}$ & $2.28^{* * *}$ & $0.27^{* * * *}$ \\
$\mathrm{SE}(\mathrm{B})$ & 0.30 & 0.30 & 0.006 \\
$\mathrm{~N}=1373$ & & & \\
PSEUDO R & & \\
NULL DEVIANCE: 2828.5 ON 1373 DEGREES OF FREEDOM \\
RESIDUAL DEVIANCE: 1889.7 ON 1371 DEGREES OF \\
FREEDOM \\
AIC: 2274.5 BIC: 2290
\end{tabular}


Table 4 Results from Poisson regression on Hp1 divided by type of procedure

\begin{tabular}{|c|c|c|c|}
\hline $\begin{array}{l}\text { ROLE OF PAPER } \\
\text { Items }\end{array}$ & Constant & Paper & Scaled Size \\
\hline \multicolumn{4}{|c|}{$\begin{array}{l}N=1356 \\
\text { PSEUDO R } 20.51 \\
\text { NULL DEVIANCE: } 2813 \text { ON } 1356 \text { DEGREES OF FREEDOM } \\
\text { RESIDUAL DEVIANCE: } 1890 \text { ON } 1354 \text { DEGREES OF FREEDOM } \\
\text { AIC: } 2272 \text { BIC: } 228\end{array}$} \\
\hline $\begin{array}{l}\text { ROLE OF EMAIL } \\
\text { Items }\end{array}$ & Constant & Email & Scaled Size \\
\hline \multicolumn{4}{|c|}{$\begin{array}{l}\mathrm{N}=1356 \\
\text { PSEUDO R }{ }^{2} 0.49 \\
\text { NULL DEVIANCE: } 2813 \text { ON } 1356 \text { DEGREES OF FREEDOM } \\
\text { RESIDUAL DEVIANCE: } 1951.7 \text { ON } 1354 \text { DEGREES OF FREEDOM } \\
\text { AIC: } 2333.7 \text { BIC: } 2349\end{array}$} \\
\hline ROLE OF IS Items & Constant & System & Scaled Size \\
\hline $\begin{array}{l}\text { B } \\
\text { SE (B) }\end{array}$ & $\begin{array}{l}-1.28^{* * *} \\
0.05\end{array}$ & $\begin{array}{l}-1.43^{* * *} \\
0.29\end{array}$ & $\begin{array}{l}0.30^{* * *} \\
0.006\end{array}$ \\
\hline \multicolumn{4}{|c|}{$\begin{array}{l}\mathrm{N}=1356 \\
\text { PSEUDO R }{ }^{2} 0.49 \\
\text { NULL DEVIANCE: } 2813 \text { ON } 1356 \text { DEGREES OF FREEDOM } \\
\text { RESIDUAL DEVIANCE: } 1962 \text { ON } 1354 \text { DEGREES OF FREEDOM } \\
\text { AIC: } 2344 \text { BIC: } 2359\end{array}$} \\
\hline $\begin{array}{l}\text { ROLE OF ENCRYPTED IS } \\
\text { Items }\end{array}$ & Constant & Anonymous System & Scaled Size \\
\hline $\begin{array}{l}\mathrm{B} \\
\mathrm{SE}(\mathrm{B})\end{array}$ & $\begin{array}{l}-1.78^{* * * *} \\
0.07\end{array}$ & $\begin{array}{l}1.55^{* * *} \\
0.10\end{array}$ & $\begin{array}{l}0.23 * * * \\
0.007\end{array}$ \\
\hline $\begin{array}{l}\mathrm{N}=1356 \\
\text { PSEUDO R }{ }^{2} 0.55 \\
\text { NULL DEVIANCE: } 2813 \text { O } \\
\text { RESIDUAL DEVIANCE: } 17 \\
\text { AIC:2159 BIC: } 2175\end{array}$ & $\begin{array}{l}\text { GREES O } \\
354 \text { DEGF }\end{array}$ & $\begin{array}{l}\text { OM } \\
\text { FREEDOM }\end{array}$ & \\
\hline
\end{tabular}

communications and structured decision making, tends to be more effective in convincing employees to blow the whistle. The positive relationship between specific procedures and whistleblowing reports is even more important if it is considered that it was observed a positive relationship between the implementation of specific procedures and the number of non-anonymous reports (Table 5).

This result can be explained by the fact that - as discussed above-in Italian culture the risk of retaliation is very real and whistleblowing is really in an early stage. So maybe it is easier to avoid risks and the probability of being identified and accused by colleagues if the employee blows the whistle in an organisation which has specific whistleblowing procedures and information flows. These kinds of procedures are fundamental to reducing the fear of retaliation and to overcoming the 
Table 5 Results from Poisson regression on Role of procedure wrt non anonymous report

\begin{tabular}{llll}
\hline ROLE OF PROCEDURE WRT NON ANONYMOUS REPORT & Constant & Procedure & Scaled Size \\
Items & & & \\
\hline B & $-4.18^{* * *}$ & $2.10^{* * *}$ & $0.17^{* * *}$ \\
SE (B) & 0.57 & 0.58 & 0.026 \\
N $=1084$ & & \\
PSEUDO R 20.04 & & \\
NULL DEVIANCE: 766 ON 1084 DEGREES OF FREEDOM & & \\
RESIDUAL DEVIANCE: 736 ON 1082 DEGREES OF FREEDOM & \\
AIC: 863.8 BIC:878 & & \\
\hline
\end{tabular}

cultural and social barriers that can be found in Italian public administrations. These results demonstrate that the effort put into developing whistleblowing procedures is worthwhile. Finally, it was investigated whether there is a relationship between the fact that an organisation used multiple channels or just one channel to receive whistleblowing reports. The results in Table 6 show a positive relation between the number of used channels and the number of whistleblowing reports.

These results are consistent with the organizational pillar for an effective anticorruption strategy defined by Yeboah-Assiamah (2017) as "systems and procedures to assess the loopholes and various windows of opportunity that are candidates for corruption". According to the author public organizations must be able to design procedures and systems "that are context-dependent to propel, promote ethical conduct and integrity, to monitor, prevent and control corruption." They are consistent also with the results of Palumbo and Manna's research (2020), that is to increase to the employees' willingness to blow the whistle it's necessary a strong organizational support, also concerning an effective protection systems and procedures to prevent whistleblowers' retaliation. The authors stated that "employees are encouraged to report organizational wrongdoings when they perceive that the organization supports them in disclosing misconduct since this strengthens the collective perception of organizational ethics (Chang et al., 2017). Hence, the greater the organizational support in designing and implementing reliable and consistent whistleblowing procedures, the higher the employees' commitment to denounce organizational wrongdoings." In addition, they also founded a positive relation between whistleblowing and procedure when employees recognize that the whistleblowing procedures are

Table 6 Results from Poisson regression on Role of the number of procedures

\begin{tabular}{|c|c|c|c|}
\hline $\begin{array}{l}\text { ROLE OF THE NUMBER OF PROCEDURES } \\
\text { Items }\end{array}$ & Constant & \# Procedures & Scaled Size \\
\hline B & $-2.61^{* * *}$ & $0.83^{* * *}$ & $0.25 * * *$ \\
\hline SE (B) & 0.10 & 0.05 & 0.007 \\
\hline \multicolumn{4}{|l|}{$\begin{array}{l}\mathrm{N}=1416 \\
\text { PSEUDO R } 20.54\end{array}$} \\
\hline \multicolumn{4}{|c|}{$\begin{array}{l}\text { NULL DEVIANCE: } 2855 \text { ON } 1416 \text { DEGREES OF FREEDOM } \\
\text { RESIDUAL DEVIANCE: } 1764 \text { ON } 1414 \text { DEGREES OF FREEDOM } \\
\text { AIC: } 2146 \text { BIC: } 2162\end{array}$} \\
\hline
\end{tabular}


Table 7 Training and education programs by year

\begin{tabular}{|c|c|c|c|c|}
\hline & 2014 & 2015 & 2016 & 2017 \\
\hline $\begin{array}{l}\% \text { and number of munici- } \\
\text { palities that have trained } \\
\text { employees }\end{array}$ & $\begin{array}{l}84 \% \\
\text { (n. 260) }\end{array}$ & $\begin{array}{l}90 \% \\
\text { (n. 306) }\end{array}$ & $\begin{array}{l}91 \% \\
\text { (n. 327) }\end{array}$ & $\begin{array}{l}92 \% \\
(345)\end{array}$ \\
\hline $\begin{array}{l}\text { Number of municipali- } \\
\text { ties respondents to this } \\
\text { section of the annual } \\
\text { report }\end{array}$ & 308 & 340 & 360 & 374 \\
\hline
\end{tabular}

Table 8 Results from Poisson regression on $\mathrm{Hp} 2$

\begin{tabular}{|c|c|c|c|}
\hline $\begin{array}{l}\text { HP2 ROLE OF TRAINING PROGRAMS } \\
\text { Items }\end{array}$ & Constant & Training & Scaled Size \\
\hline B & $-2.40^{* * *}$ & $1.15^{* * *}$ & $0.29 * * *$ \\
\hline SE (B) & 0.27 & 0.28 & 0.006 \\
\hline \multicolumn{4}{|l|}{$\begin{array}{l}\mathrm{N}=1374 \\
\text { PSEUDO R }{ }^{2} 0.47\end{array}$} \\
\hline \multicolumn{4}{|c|}{$\begin{array}{l}\text { NULL DEVIANCE: } 2829.0 \text { ON } 1374 \text { DEGREES OF FREEDOM } \\
\text { RESIDUAL DEVIANCE: } 1987.4 \text { ON } 1372 \text { DEGREES OF FREEDOM } \\
\text { AIC: } 2372 \text { BIC: } 2388\end{array}$} \\
\hline
\end{tabular}

actually tailored and designed to protect them against retaliations (Cho \& Song, 2015).

\section{The Relationship between Training and Anti-Corruption Education Programs and Whistleblowing Reports}

As regards training and anti-corruption education programs, it is found a similar trend to the other variable. As shown in Table 7, in 2014 just 260 municipalities trained their employees on ethics and anti-corruption. The situation started to change in 2015 when the number rose to 306 municipalities, in 2016 the number was 327 , and finally in 2017, 345 municipalities provided training for their employees. This trend is highlighted also in the number of respondents to this section of the annual survey: 308 respondents in 2014, 340 in 2015, 360 in 2016 and 374 (out of 400) in 2017.

These results confirm a positive trend in the investment in training on anti-corruption systems. The research hypothesis was that whistleblowers report wrongdoing when they are aware of the procedures, of the context and of the opportunity to blow the whistle. They have to perceive a culture of transparency and of organisational justice, without any fear of being fired or of retaliation if they do the right thing. These results confirm this research hypothesis, by finding a highly significant relationship between training and education programs and whistleblowing reports (Table 8). 
Education and training certainly help whistleblowers to rationalise the difficult decision to report a wrongdoing instead of remaining silent, and give a cognitive justification to the negative consequences of whistleblowing. As stated by Gong et al. (2015) it is crucial to address the deficit in people's understanding of corruption in order to promote the effectiveness of anti-corruption systems. This step is critical, since whistleblowers have a strong need to reduce pressures, tensions and discomfort in order to justify their act. Integrity must be visible and steadily communicated. Conversely the risk is that the normal management chain is not sufficient to deal with whistleblowing and to encourage disclosure practices. Also, from a more practical point of view, all the people involved in the whistleblowing process must be aware of their responsibilities and their obligations, what happens before and after their actions, how to identify and address risks, and how to put in place support mechanisms to make the act of blowing the whistle easier. Finally, it has to consider that in a country as Italy, frequent exposure and the perception of high level of corruption tend to make people habituated to it. Hence, education and training are crucial to avoid that corruption becomes a routine affair that causes people to become inured and less conscious than they should be. And in these education and training program, political commitment and will to contrast corruption play a crucial role. As demonstrated by Quah (2011) the lack of political commitment was perceived by citizens as the most critical factor which leads to citizens beliefs about corruption and their attitudinal changes. These results are consistent with Tantardini and Garcia-Zamor's research (2015), and in particular pointing out the importance of culture as determinant of high level of trust and compliance to norms, and also of an organizational social capital that are indispensable prodromal conditions for successfull anticorruption policies. These results are consistent also with the first pillar of an anticorruption system that Yeboah-Assiamah (2017) calls "strong personalities" defined as "public officials that develop their personal ethics and integrity levels for their own sake and that of the organization". As stated by the author "It is not enough to institute complex organizational systems, rules, procedures and mechanisms. Spending quality time and resources in developing complex system without a corresponding time and resources in developing the integrity levels of people will make the system dysfunctional."

\section{Conclusions}

According to Van Schoor (2017) corruption is "one of the most pressing problems of our globalised world"; Rothstein \& Varraich (2017) define corruption as "on the priority agenda of both political/social scientists as well as policy makers". As discussed above, whistleblowing is one of the most relevant and effective ways to encourage people not to look the other way when wrongdoing occurs. The research demonstrates how whistleblowing is still in an embryonic stage in Italy. Following the first year of implementation (2014) when there were some criticisms and a low responsiveness to change, the next 3 years show a consistent increase in the number of reports and in the number of municipalities adopting a procedure for whistleblowing, as well an increase in the implementation of more sophisticated procedures; notably, systems with dedicated 
encryption that protect the informant's identity, which play a fundamental role in contrasting the fear of retaliation and employment discrimination. As regards education and training programs on ethics and anti-corruption systems it can be observed the same trend. In 2014 one fifth of the observed municipalities had not organised any course. In 2017 almost all the municipalities had activated education and training programs. Summarising the relationships between the determinants of whistleblowing and the actual reporting of wrongdoing, it is possible to make the following two considerations. First, both the existence and clarity of whistleblowing procedures and the quality of tools used to report the wrongdoing make the difference. This can be explained by the fact that in Italian culture the risk of retaliation is very real. It is much easier to avoid risks and the probability of being identified and accused by colleagues if the employee is able to blow the whistle through specific procedures and information flows. Second, training and education programs too are very important determinants and were found to have a positive impact on whistleblower reporting. The skills and knowledge the whistleblowers gained thanks to education and training programs led to increased opportunities to actually blow the whistle, also by reducing the pressures and constraints related to the natural discomfort felt by whistleblower, that certainly has cultural roots. As wrote by the Group of states against corruption-Greco (2009) the fight against corruption in Italy, "requires a long term approach and sustained political commitment; combating corruption has to become a matter of culture and not only rules". And the implementation of whistleblowing systems, with clear and performing procedures and also strengthened by education and training programs is one of the few weapons that a community can use to prevent and contrast corruption in an effective way.

Funding Open access funding provided by Università degli Studi di Pavia within the CRUI-CARE Agreement.

\section{Declarations}

Limitations and Directions for Future Research Considering that the research is limited to 400 Italian municipalities it is necessary to be careful about generalising these results. It would be worthwhile extending this analysis to other sectors of public administrations as well as to other countries and/or private companies. In addition, the research focuses on only two variables due to the availability of data provided by ANAC, but it is clear that this is an oversimplification of the observed phenomena. Future studies could include external whistleblowing, as well as an analysis of the relationship between the determinants of whistleblowing and the various types of wrongdoing. Finally, it would also be worthwhile studying the organisational level, by developing individual case studies.

No funds, grants, or other support was received.

The authors have no relevant financial or non-financial interests to disclose.

Open Access This article is licensed under a Creative Commons Attribution 4.0 International License, which permits use, sharing, adaptation, distribution and reproduction in any medium or format, as long as you give appropriate credit to the original author(s) and the source, provide a link to the Creative Commons licence, and indicate if changes were made. The images or other third party material in this article are included in the article's Creative Commons licence, unless indicated otherwise in a credit line to the material. If material is not included in the article's Creative Commons licence and your intended use is not permitted by statutory regulation or exceeds the permitted use, you will need to obtain permission directly from the copyright holder. To view a copy of this licence, visit http://creativecommons.org/licen ses/by/4.0/. 


\section{References}

Akimova, L., Litvinova, I., Ilchenko, H., Pomaza-Ponomarenko, A., \& Yemets, O. (2020). (2020), The Negative Impact of Corruption on the Economic Security of States. International Journal of Management, 11(5), 1058-1071.

Association of Certified Fraud Examiners. (2018). Report to the nations on occupational fraud and abuse. Association of Certified Fraud Examiners, Inc.

Barnett, T. (1992). A Preliminary Investigation of the Relationship Between Selected Organizational Characteristics And External Whistleblowing By Employees. Journal of Business Ethics, 11(12), 949-959.

Baniamin, H. M., \& Jamil, I. (2018). Dynamics of Corruption and Citizens' Trust in Anti-Corruption Agencies in Three South Asian Countries. Public Organization Review, 18, 381-398.

Bauhr, M., \& Charron, N. (2020). The EU as a savior and a saint? Corruption and public support for redistribution. Journal of European Public Policy, 27(4), 509-527.

Caillier, J. G., \& Sa, Y. (2017). Do transformational-oriented leadership and transactional-oriented leadership have an impact on whistle-blowing attitudes? A longitudinal examination conducted in US federal agencies. Public Management Review, 19(4), 406-422.

Calderon, R., Pinero, R., \& Redin, D. M. (2018). Can compliance restart integrity? Toward a harmonized approach. The example of the audit committee. Business Ethics-a European Review, 27(2), 195-206.

Capasso, S., Goel, R. K., \& Saunoris, J. W. (2019). Is it the gums, teeth or the bite? Efectiveness of dimensions of enforcement in curbing corruption. Economics of Governance, 20(4), 329-369.

Cassematis, P. G., \& Wortley, R. (2013). Prediction of Whistleblowing or Non-reporting Observation: The Role of Personal and Situational Factors. Journal of Business Ethics, 117(3), 615-634.

Chan, K., Dang, V., \& Li, T. (2020). Corruption and Income Inequality in China. Emerging Markets Finance and Trade, 56(14), 3351-3366.

Chang, Y., Wilding, M., \& Shin, M. C. (2017). Determinants of Whistleblowing intention: Evidence from the South Korean Government. Public Performance and Management Review, 40(4), 676-700.

Cheng, J., Bai, H. Q., \& Yang, X. J. (2019). Ethical Leadership and Internal Whistleblowing: A Mediated Moderation Model. Journal of Business Ethics, 155(1), 115-130.

Cho, Y. J., \& Song, H. J. (2015). Determinants of Whistleblowing within government agencies. Public Personnel Management, 44(4), 450-472.

Chordiya, R., Sabharwal, M., Relly, J., \& Berman, E. (2020). Organizational protection for whistleblowers: A cross-national study. Public Management Review, 22(4), 527-552.

Cooper C. (2021). Encouraging bureaucrats to report corruption: human resource management and whistleblowing, Asia Pacific Journal of Public Administration, 4,1-14.

Cooray, A., Dzhumashev, R., \& Schneider, F. (2017). How Does Corruption Affect Public Debt? An Empirical Analysis, World Development, 90, 115-127.

Culiberg, B., \& Mihelic, K. K. (2017). The Evolution of Whistleblowing Studies: A Critical Review and Research Agenda. Journal of Business Ethics, 146(4), 787-803.

De Graaf, G. (2019). What Works: The Role of Confidential Integrity Advisors and Effective Whistleblowing. International Public Management Journal, 22(2), 213-231.

European Commission. (2014). Report from the commission to the council and the European Parliament: Annex 12 Italy to the EU Anti-Corruption Report. Bruxelles

Gong, T., Wang, S., \& J. \& Ren. . (2015). Corruption in the Eye of the Beholder: Survey Evidence from Mainland China and Hong Kong. International Public Management Journal., 18(3), 458-482.

GRECO - Group of State against Corruption. (2009). Evaluation report. Bruxelles.

Gundlach, M. J., Douglas, S. C., \& Martinko, M. J. (2003). The decision to blow the whistle: A social information processing framework. Academy of Management Review, 28(1), 107-123.

Hassink, H., de Vries, M., \& Bollen, L. (2007). A content analysis of whistleblowing policies of leading european companies. Journal of Business Ethics, 75(1), 25-44.

Keenan, J. P. C. F., \& p. d. W. . (1990). Upper-Level Managers and Whistleblowing: Determinants of Perceptions of Company Encouragement and Information about Where to Blow the Whistle. Journal of Business and Psychology, 5(2), 223-235.

King, G. (1999). The implications of an organization's structure on whistleblowing. Journal of Business Ethics, 20(4), 315-326.

KPMG. (2016). Global profiles of the fraudster. KPMG International. 
Liu, C., Moldogaziev, T. T., \& Mikesell, J. L. (2017). Corruption and State and Local Government Debt Expansion. Public Administration Review, 77, 681-690.

Mansbach, A. (2007). Political surplus of whistleblowing: a case study, Business Ethics, 16 (2), $124-131$.

Mazerolle, P. and A. J. Brown. (2008). Support for whistleblowing among managers: Exploring job satisfaction and awareness of obligations. In: A.J. Brown (Eds.). Whistleblowing in the Australian public sector enhancing the theory and practice of internal witness management in public sector organisations (pp. 165-181). ANU Press.

Mesmer-Magnus, J. R., \& Viswesvaran, C. (2005). Whistleblowing in organizations: An examination of correlates of whistleblowing intentions, actions, and retaliation. Journal of Business Ethics, 62(3), 277-297.

Miceli, M. P., Near, J. P., \& Dworkin, T. M. (2009). A Word to the Wise: How Managers and Policy-Makers can Encourage Employees to Report Wrongdoing. Journal of Business Ethics, 86(3), 379-396.

Miceli, M. P., Near, J. P., \& Schwenk, C. R. (1991). Who Blows The Whistle And Why. Industrial \& Labor Relations Review, 45(1), 113-130.

Palumbo, R., \& Manna, R. (2020). Uncovering the relationship between whistleblowing and organizational identity Some preliminary evidence from Italian publicly owned universities. International Journal of Public Sector Management, 33(1), 94-112.

Park, H., \& Lewis, D. (2019). The motivations of external whistleblowers and their impact on the intention to blow the whistle again. Business Ethics: A European Review, 28(3), 379-390.

Pearce, F., \& Snider, L. (1995). Corporate Crime Contemporary Debates. University of Toronto Press.

Persson, A., Rothstein, B., \& Teorell, J. (2013). Why anticorruption reforms fail-Systemic corruption as a collective action problem. Governance, 26(3), 449-471.

Peerthum, S., \& Luckho, T. (2021). Exploring the Linkage Between Public Corruption and Political Trust in Mauritius: A PLS-SEM Approach. Public Organization Review, 21, 317-335.

Previtali, P., \& Cerchiello, P. (2017). Structuring supervisory board for an anti-corruption strategy: A new application of a compliance system. Corporate Governance, 17(1), 48-63.

Previtali, P., \& Cerchiello, P. (2018a). The Prevention of Corruption as an Unavoidable Way to Ensure Healthcare System Sustainability. Sustainability, 10, 3071.

Previtali, P., \& Cerchiello, P. (2018b). The determinants of whistleblowing in public administrations: An analysis conducted in Italian health organizations, universities, and municipalities. Public Management Review, 20(11), 1683-1701.

Quah, J.S., \& Jones, L. (2011) Curbing corruption in Asian countries: An impossible dream? Emerald Group Publishing Limited.

Rachagan, S., \& Kuppusamy, K. (2013). Encouraging Whistle Blowing to Improve Corporate Governance? A Malaysian Initiative. Journal of Business Ethics, 115(2), 367-382.

Rothstein, B., \& Torsello, D. (2013). Is corruption understood differently in different cultures? Anthropology meets political science. Journal of Anthropological Research, 70(2), 263-288.

Rothstein, B., \& Varraich, A. (2017). Making sense of corruption. Cambridge University Press

Schomaker, R. M. (2020). Conceptualizing Corruption in Public Private Partnerships. Public Organiz Rev, 20, 807-820.

Shah, A. (2007). Tailoring the fight against corruption to country circumstances. In: Shah (Eds.), Performance accountability and combucting corruption. The World Bank.

Smaili, N., \& Arroyo, P. (2019). Categorization of Whistleblowers Using the Whistleblowing Triangle. Journal of Business Ethics, 157(1), 95-117.

Smith, R. (2010). The Role of Whistle-Blowing in Governing Well: Evidence From the Australian Public Sector. American Review of Public Administration, 40(6), 704-721.

Tantardini, M., \& Garcia-Zamor, J. C. (2015). Organizational Social Capital and Anticorruption Policies: An Exploratory Analysis. Public Organization Review, 15, 599-609.

Taylor, J. (2018). Internal Whistle-Blowing in the Public Service: A Matter of Trust. Public Administration Review, 78(5), 717-726.

Van Schoor, B. (2017). Fighting corruption collectively: How successful are sector-specific coordinated governance initiatives in curbing corruption. Springer VS.

Vandekerckhove, W. (2018). Whistleblowing and Information Ethics: Facilitation, Entropy, and Ecopoiesis. Journal of Business Ethics, 152(1), 15-25.

Vandekerckhove, W., \& Lewis, D. (2012). The Content of Whistleblowing Procedures: A Critical Review of Recent Official Guidelines. Journal of Business Ethics, 108(2), 253-264.

Vandekerckhoye, W., \& Phillips, A. (2019). Whistleblowing as a Protracted Process: A Study of UK Whistleblower Journeys. Journal of Business Ethics, 159(1), 201-219. 
Yeboah-Assiamah, E. (2017). 'Strong Personalities' and 'Strong Institutions' Mediated by a 'Strong Third Force': Thinking 'Systems' in Corruption Control. Public Organization Review, 17, 545-562.

Wu, S., Li, B., Nie, Q., \& Chen, C. (2017). Government expenditure, corruption and total factor productivity. Journal of Cleaner Production, 168, 279-289.

Publisher's Note Springer Nature remains neutral with regard to jurisdictional claims in published maps and institutional affiliations. 